\title{
A Macroeconomic News Index for Constructing Nowcasts of U.S. Real Gross Domestic Product Growth
}

\author{
Sean P. Grover, Kevin L. Kliesen, and Michael W. McCracken
}

\begin{abstract}
Analyzing the performance of the economy in real time is a challenge for those who must forecast macroeconomic variables such as inflation or employment. A key aspect of this challenge is evaluating the incoming flow of information contained in economic announcements. In this article, the authors develop a simple-to-read index of these announcements that they then use to construct nowcasts. The index tracks whether key economic data have come in stronger, weaker, or as expected during the current quarter relative to a baseline consensus forecast. Specifically, the data releases are weighted relative to their importance in updating forecasts of real gross domestic product growth during the current quarter. (JEL C22, C53, E37)
\end{abstract}

Federal Reserve Bank of St. Louis Review, Fourth Quarter 2016, 98(4), pp. 277-96. http://dx.doi.org/10.20955/r.2016.277-296

A nalyzing the performance of the economy in real time is a challenge for those who must forecast important macroeconomic variables such as inflation or employment. A key aspect of this challenge is evaluating the incoming flow of information contained in economic announcements. Thus, if important economic data are stronger than forecasters and financial market participants expected, this information could be a signal to economic policymakers and others that the economy is strengthening. The opposite is true as well. This news signal is often called the unexpected, or "surprise," component of economic information flows (announcements).

Many central banks and private forecasters have used these economic announcements to develop methods for forecasting the current-quarter's real gross domestic product (GDP) growth. Because these processes track the evolution of the economy's performance in real time ("now"), they are sometimes called "nowcasts" or "tracking forecasts." There are several types of nowcast methodologies. ${ }^{1}$ For instance, some economists and economic consulting firms use a GDP accounting approach based on key data releases such as Census Bureau reports on retail sales or construction spending. Many of these reports provide the underlying data_known as "source data" - used by the Bureau of Economic Analysis (BEA) to compile

Sean Grover is a former research assistant, and Kevin L. Kliesen and Michael W. McCracken are research officers and economists at the Federal Reserve Bank of St. Louis. Lowell R. Ricketts and Joseph T. McGillicuddy provided research assistance.

○ 2016, Federal Reserve Bank of St. Louis. The views expressed in this article are those of the author(s) and do not necessarily reflect the views of the Federal Reserve System, the Board of Governors, or the regional Federal Reserve Banks. Articles may be reprinted, reproduced, published, distributed, displayed, and transmitted in their entirety if copyright notice, author name(s), and full citation are included. Abstracts, synopses, and other derivative works may be made only with prior written permission of the Federal Reserve Bank of St. Louis. 


\section{Grover, Kliesen, McCracken}

its quarterly estimates of GDP and its components. $\stackrel{2}{-}$ Other economists, including Giannone, Reichlin, and Small (2008), have used more sophisticated factor-based methods that use a large number of economic data series, regardless of whether these data are used as source data for GDP and its components.

This article describes a different approach. Our approach augments a consensus forecast of current-quarter real GDP growth by adding the news component of several key economic data releases. To do so, we first create an "economic news index" (ENI) based on the surprise component of key monthly economic data releases and then use that index to update Blue Chip Consensus (BCC) forecasts of real GDP growth as we move across the quarter.

Although our approach appears to be distinct relative to other forecast tracking methods, our experience is that no single approach seems to dominate all others all of the time. Thus, our method serves as another technique that economists, forecasters, and policymakers can use to assess the performance of the economy in real time. The first two sections of this article briefly describe the various methods economists and forecasters have adopted to track and forecast U.S. economic conditions-chiefly through estimates of real GDP growth. In the third section, we discuss the construction of the ENI and how it is used to update BCC forecasts of real GDP growth as we move across the quarter. The fourth section assesses the predictive power of this new procedure.

\section{NOWCASTING: TWO APPROACHES}

On an average trading day, government statistical agencies and private sector organizations release reports that provide a snapshot of economic conditions over the previous day, week, month, or quarter. Many of these reports provide the source data that the BEA uses to construct its quarterly estimates of GDP. Some forecasters have used this data flow to piece together an estimated dollar value of real GDP prior to the release of the advance estimate. In this latter framework, current-quarter estimates of real GDP are constructed by estimating bridge equations for its major components, such as real personal consumption expenditures

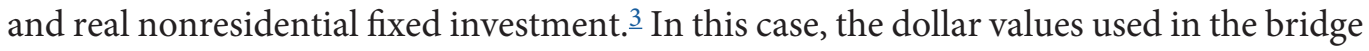
equations flow from key monthly source data such as retail sales, residential construction, durable goods shipments and inventories, wholesale inventories, and exports and imports. The annualized percentage difference between the current-quarter estimate in level terms and the previous-quarter estimate in level terms is thus the current-quarter nowcast.

Often the bridge equations are conditioned on an existing current-quarter forecast from a multi-equation forecasting model that embeds assumptions about the path of the key source data. For example, suppose a macroeconomic consulting firm runs its forecasting model in late February and predicts that real residential fixed investment will increase at a 5 percent annual rate in the first quarter. This forecast is conditioned on several factors. These include the actual value of housing starts in January and an assumed (predicted) value for housing starts in February and March. When the actual estimates of February housing starts are released in mid-March, the bridge equation will adjust the forecast for first-quarter real GDP 
based on its forecast error (if any) for February housing starts. This process is repeated for other source data that are mapped into the quarterly real GDP components. 4

There are several limitations that this accounting approach — and indeed, most real-time tracking methods-must overcome: Key monthly source data are sample-based estimates subject to repeated revision as new information becomes available. For example, prior to the release of the advance estimate for real GDP growth in 2014:Q1, many tracking estimates were above 1 percent (annualized). The consensus of professional forecasters (Blue Chip Economic Indicators) as of April 10, 2014, was that real GDP would increase at a rate of about 1.7 percent rate in the first quarter. However, when the advance estimate was published on April 30, the BEA reported that real GDP had increased by only 0.1 percent at an annual rate. Subsequent revisions lowered the estimate for 2014:Q1 to -1.0 percent (second estimate) and to -2.9 percent (third estimate). Then, in July 2014, the annual revision raised this estimate to -2.1 percent. Thus, while it may seem intuitive to rely exclusively on source data for the national income and product accounts, there are certainly disadvantages with this approach to constructing estimates of real GDP.

A second popular method for constructing current-quarter forecasts is based on factor models. One variant of this approach uses statistical methods to extract a single latent variable-termed a factor, or index-from a large number of data series. This single variable is then used to forecast real GDP growth or consumer price index (CPI) inflation in a regressionbased framework. $\underline{5}$ As with all forecasting, this segment of the nowcasting literature intends to produce a forecast that minimizes a quadratic loss function and does so with up-to-date, real-time data. Principal components and state-space models that use the Kalman filter are the most common approaches to constructing these factors.

These and other forecasting methods are discussed in greater detail in the two Handbook of Economic Forecasting volumes. For example, in one chapter, Stock and Watson (2006) discuss the use of principal components analysis in a dynamic factor model framework. This method is the most common in the literature and is used in a wide range of macroeconomic and financial applications. Other issues associated with factor analysis are discussed in a second chapter by Bańbura et al. (2013). We refer interested readers to the Handbook references for other approaches not outlined in our article. For now, we merely note that many institutions, such as central banks, use factor models to capture the comovement of macroeconomic variables to improve predictability of their preferred target variables.

\section{USING DATA SURPRISES TO ASSESS CHANGES IN ECONOMIC MOMENTUM}

For policymaking purposes, the Federal Open Market Committee (FOMC) regularly communicates to the public that its policy is data dependent. 6 That is, the current and prospective stance of monetary policy will depend on the performance of the economy and the near-term forecasts for real GDP and other key variables. $\underline{7}$ Thus, if important economic data such as employment, retail sales, and industrial production repeatedly surprise to the upside (downside), then this could be a signal that forecasters have been underestimating (overesti- 
Figure 1

\section{Citi Economic Surprise Index and Real GDP Growth}

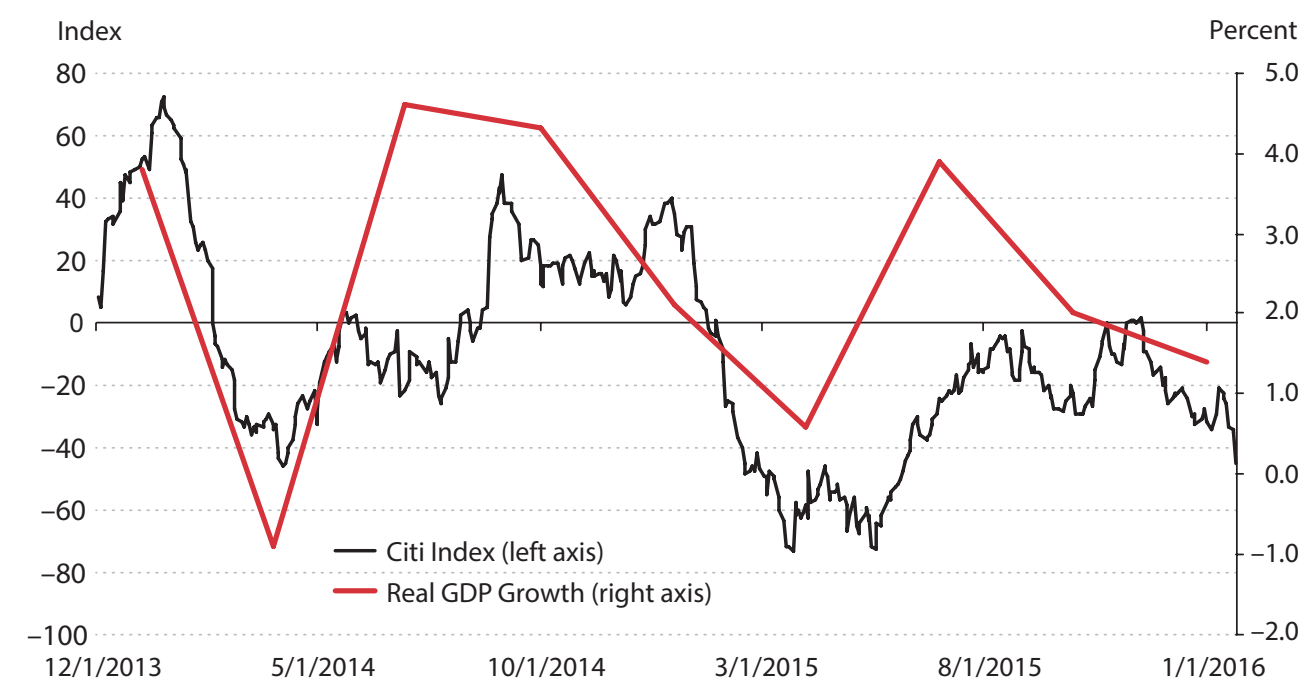

SOURCE: Citigroup, Haver Analytics, and BEA.

mating) the strength of the economy. For instance, suppose retail sales are expected to increase by 0.5 percent in February, but the Census Bureau instead reports that retail sales fell by 0.5 percent. In this case, the "news," or surprise, that moves markets is the difference between -0.5 percent and 0.5 percent, or -1 percentage point. This matters because, all else equal, if retail sales are smaller than expected, then the expectations for real personal consumption expenditures in the first quarter would be adjusted downward. The result would be slower growth of real GDP. Of course, the analyst must remember that retail sales, like other key monthly variables, can be highly volatile and, importantly, can be revised substantially from month to month.

The Citi Economic Surprise Index, which is largely constructed from methodology proposed by James and Kasikov (2008), is one well-known attempt to gauge the strength or weakness of the economy based on data surprises. Citi's method assigns unconditional weights to different surprises and uses an exponential decay to discount older surprises. The index is then normalized by exchange rate returns. Figure 1 shows that although the Citi index can be volatile, it does seem to have some ability to detect changes in economic momentum-as reflected in changes in real GDP growth from quarter to quarter.

Figure 2 shows an even simpler approach a practitioner can adopt to gauge changes in economic momentum in real time based on data surprises. $\frac{8}{\text { In }}$ this figure, a net tracking indicator (NTI) is calculated based on the flow of key data released between December 2, 2013, and January 21, 2016. Successful use of this framework requires a measure of market expectations. Examples of key data flows are retail sales, payroll employment, housing starts, and international trade. 9 The NTI is constructed in the following manner. First, for each release, 


\section{Figure 2}

\section{Net Tracking Indicator and Real GDP Growth}

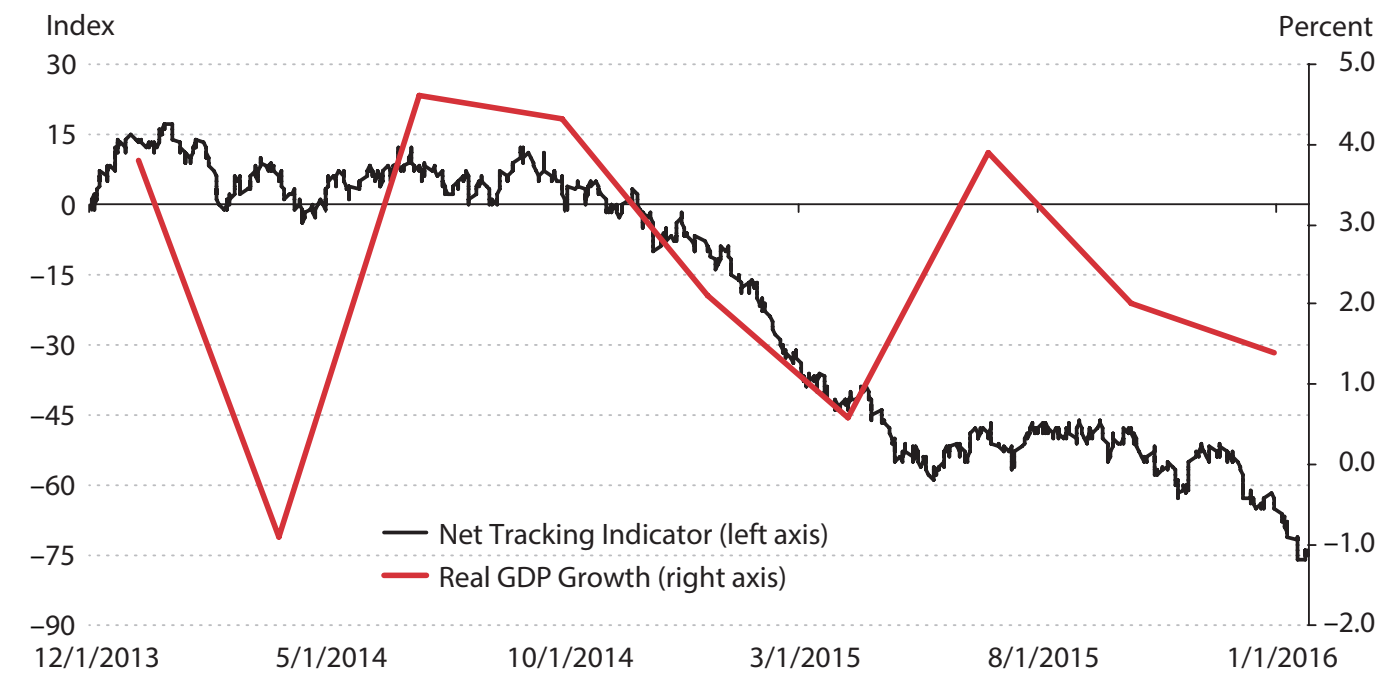

SOURCE: Authors' calculations, Haver Analytics, and BEA.

determine whether the data were weaker or better than expected relative to some measure of market expectations. Second, if the data were better than expected, arbitrarily assign a value of +1 ; if weaker than expected, assign a value of -1 . If the data met expectations, then assign a value of 0 . Third, cumulate the indicator values $(+1,-1$, and 0$)$ over the course of the time period. Figure 2 indicates that the NTI also does a reasonable job of tracking changes in economic momentum - as measured by the quarter-to-quarter change in real GDP growth.

Interpreting the NTI is relatively straightforward since it is conditional on one's assumption about the direction of the expected change in economic activity. And since much of the data feed directly into estimates of real GDP, or are indicators of economic activity more broadly, the NTI is thus one proxy for the expected change in real economic activity in a given quarter. But there are some significant drawbacks to this simplistic approach. Perhaps the most obvious is that each data point receives an equal weight. For example, the NTI gives the surprise component of consumer confidence the same weight as the surprise component of retail sales; the latter is more economically significant for estimating real GDP. In the next section, we develop a method for assigning weights to key data surprises and then mapping these weight-adjusted flows into a nowcast for current-quarter real GDP growth.

\section{THE ECONOMIC NEWS INDEX}

In this section, we outline our approach to estimating an ENI that we then use to update $\mathrm{BCC}$ forecasts as we move across the current quarter. $\underline{10}$ Our methodology builds on the 


\section{Grover, Kliesen, McCracken}

strengths of the NTI approach but in a manner that overcomes many of the NTI's shortcomings. Like the NTI and the Citi Economic Surprise Index, the ENI uses surprises as the predictors. Our approach uses both National Income and Product Accounts (NIPA) source data and non-NIPA data.

\section{Data}

The predictors we use are the surprise component of common macroeconomic variables including, among others, the Institute for Supply Management (ISM) Purchasing Managers Index and the unemployment rate. As noted previously, the surprise component is just a forecast error-the difference between the value that is released by the statistical agency and the forecasted value for that individual series. The forecasts we use are those associated with the median responses of market participants surveyed by Action Economics. If there is a missing value, then survey results from Informa Global Markets are used. We do not revise the responses if the initial data value is subsequently revised. 11 Our target variable is the percent change in quarterly real GDP, expressed as a compounded annual rate. All data are available starting in 1992:Q1.

While the target variable we want to forecast is current-quarter real GDP growth, the dependent variable in our model is not. Instead, we anchor our nowcasts to that of the BCC and in doing so define our dependent variable ( $y_{t}$ used later) as their implied forecast error. Specifically, $y_{t}$ is defined as the realized value of real GDP growth minus the BCC forecast from either the February, May, August, or November Blue Chip Economic Indicators reports corresponding to quarter $t$ as the first, second, third, or fourth quarter of the year. These surveys are typically conducted on the first and second business days of the month and are released to the public three days after the surveys are returned. Since nearly all economic data for the quarter are released with a one-month lag, the current-quarter surprises are nearly all observed after the BCC current-quarter forecast from these four reports. Having defined $y_{t}$ in this way, our nowcast of current-quarter real GDP growth follows from a two-step approach. First, we use a model to predict the forecast error $\left(y_{t}\right)$ associated with the BCC forecast given the surprises obtained up to a given point within the quarter. We then simply add the BCC forecast to that value to obtain a nowcast of current-quarter real GDP growth. $\underline{12}$

One important assumption made for our model is the presence of a consistent timetable for the data releases. Typically, data releases follow a standard pattern, in that some are released early in the month, some are released mid-month, and some are released toward the end of the month. For example, the ISM manufacturing report is always released on the first business day of the month, and the employment report is usuallythough not always - released on the first Friday of the month. For each month of the quarter, we track 22 monthly frequency data releases. Additionally, we add the second and third estimates of the previous quarter's real GDP growth from the BEA. Thus, we have 68 data releases that we use to construct the surprises $x_{i, t} i=1, \ldots, 68$ within the current-quarter $t$ that constitute our predictors of $y_{t}$. Figure 3 shows these predictors and the order in which we assume they are released. 
Grover, Kliesen, McCracken

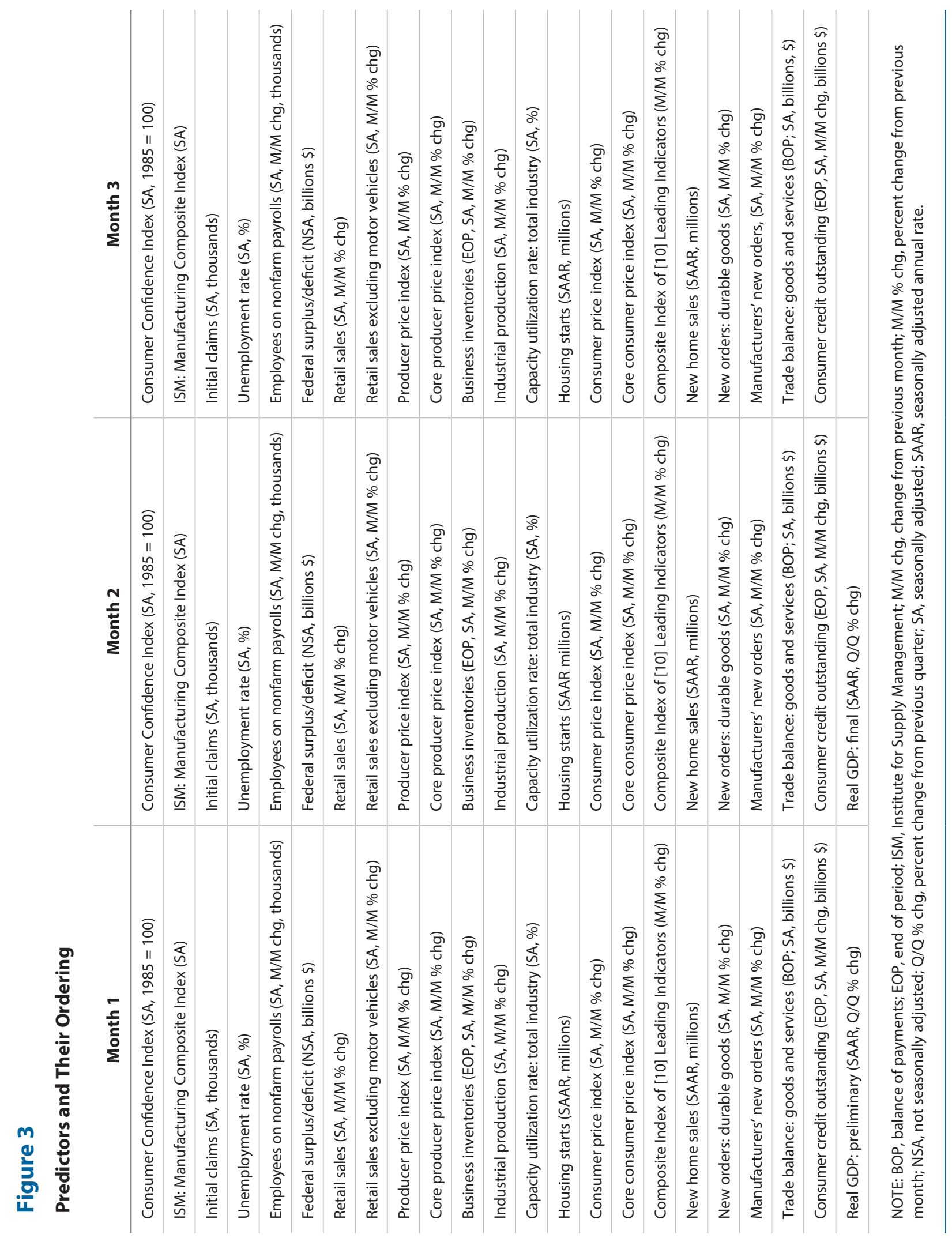




\section{The Three-Pass Regression Filter}

As noted, we use the 3PRF to estimate the weights in our ENI. The main advantage of this approach is that it allows us to construct weights for the relevant surprises with an eye toward a specific dependent variable-in this case, the current-quarter forecast error associated with the BCC forecast for real GDP growth. As one would assume, given the name, construction of the 3PRF is available in a three-step procedure involving three distinct OLS regressions. Suppose we have $N$ predictors $x_{i, t} i=1, \ldots, N$ and a scalar dependent variable $y_{t}$ observed sequentially across $T$ quarters ranging from $t=1, \ldots, T$. Suppose also that we have a proxy variable $z_{t}$ that is contemporaneously correlated with the dependent variable. ${ }^{1}$ The 3PRF follows the three stages below:

(i) Run time-series regression of $x_{i}$ on $z$ for $i=1, \ldots, N$, $x_{i, t}=\phi_{0, i}+z_{t} \phi_{i}+\varepsilon_{i, t}$, retain slope estimate $\hat{\phi}_{i}$.

(ii) Run cross-sectional regression of $x_{t}$ on $\hat{\phi}_{i}$ for $t=1, \ldots, T$, $x_{i, t}=\zeta_{0, t}+\hat{\phi}_{i} f_{t}+u_{i, t}$, retain slope estimate $\hat{f}_{t}$.

(iii) Run time-series regression of $y$ on the predictive factor $\hat{f}_{t}$, $y_{t}=\beta_{0}+\hat{f}_{t} \beta=\eta_{t}$, delivers forecast $\hat{y}_{T+1}=\hat{\beta}_{0, T}+\hat{f}_{T+1} \hat{\beta}_{T}$.

The first two stages "automatically" create the weights $w_{i, t}$ used to define the index $\hat{f}_{t}=w_{1, T} x_{1, t}+\ldots+$ $W_{N, T} x_{N, t}$ that is an output of the second stage. The final stage is simply a regression that uses the index to predict the dependent variable. A closed-form solution for these weights can be found in equation (2) of Kelly and Pruitt (2015).

1 See Kelly and Pruitt (2015) for a discussion of and examples of proxy selection. We use the default proxy in which we simply set $z$ equal to $y$.

\section{Methodology}

Our index is a linear combination of the 68 predictors $x_{i, t} i=1, \ldots, 68$. We construct these weights using the three-pass regression filter (3PRF) developed by Kelly and Pruitt (2015) (see the boxed insert). Before delineating this approach it is useful to describe why we do not use the more common factor-based approach based on principal components alluded to earlier. This may seem odd given that the principal components method is quite standard and is the basis for the construction of many economic indexes-such as the Chicago Fed National Activity Index (CFNAI) and the St. Louis Fed Financial Stress Index (STLFSI). It may seem even odder given that some studies, including Brave and Butters (2014), have shown that the CFNAI can be useful for predicting real GDP growth. Our rationale is based on the difference between the data used to construct the CFNAI and the data we use to construct our index. Put simply, the CFNAI is based on a number of series, including industrial production, that are already known to be useful for predicting real GDP growth and hence it is not surprising that the CFNAI, which is just a linear combination of these series, might be useful for predicting real GDP growth.

In contrast, our dataset does not include industrial production per se, but rather includes only the news component associated with the industrial production release. Since a priori there is no reason to think this would be a useful predictor of the current-quarter forecast error associated with the BCC forecast for real GDP growth, there is no reason to think that a principal-components-based factor would be useful for predicting it either. Mathematically, 
factors estimated using principal components are chosen to maximize the percent of variation in the predictors $x_{i, t}$ explained by that factor without any reference to any dependent variable $y_{t}$ that we are trying to predict. The $3 \mathrm{PRF}$ is one approach to linking construction of the factor relative to the dependent variable you want to predict. Specifically, it is explicitly designed to estimate the factor (i.e., index) in such a way as to maximize the covariation between the predictors $x_{i, t}$ and the dependent variable $y_{t} \cdot \frac{13}{}$ It is also worth noting that unlike the NTI, which arbitrarily determines whether a data release is better or worse than expected, and with equal weights, the 3PRF does not take a normative stance on the data. Rather, the weights are allowed to reflect predictive content for the dependent variable.

Time-Varying Versus Fixed Weights. We experiment with two different methods for estimating the weights for the data surprises and constructing the subsequent forecasts. The first approach is perhaps the most natural. As we move across time within the quarter from one data release to the next, the number of predictors that we know increases and hence the number of surprises used to construct the index increases. For example, suppose we are constructing the index at the end of February-the end of the first month of incoming data. When we apply the 3PRF, we obtain a collection of weights for those $23(N)$ surprises. Our index is then the sum of the products of the 23 surprises and their weights estimated on that day. Now consider the last day of March. When we apply the 3PRF, we obtain a collection of weights for the $46(N)$ surprises currently available. As before, our index is then the sum of the products of the 46 surprises and their weights estimated on that day. This approach implies that the weights on the surprises obtained in February are time-varying in the sense that as more surprises are realized across the quarter, the weights on the surprises obtained in February change. Of course, the same is true for the surprises obtained in March as we reapply the $3 \mathrm{PRF}$ across releases obtained in April. 14

To clarify this approach, suppose we just obtained the $i$ th surprise $x_{i, T+1}$ (for $i=1, \ldots, 68$ ) in quarter $t=T+1$ and suppose we have $T$ historical quarters. We apply the $3 \mathrm{PRF}$ to the historical surprises $x_{1, t}, \ldots, x_{i, t}$ for $t=1, \ldots, T$. This produces weights $w_{1, T}^{(i)}, \ldots, w_{i, T}^{(i)}$ that can be used to construct the index $\hat{f}_{i, T+1}=w_{1, T}^{(i)} x_{1, T+1}+\ldots+w_{i, T}^{(i)} x_{i, T+1}$ associated with all surprises received as of the $i$ th release in quarter $T+1$. The 3 PRF uses this index to construct a forecast of the dependent variable in quarter $T+1$ based on an ordinary least squares (OLS) regression of the form $y_{t}=\beta_{0 i}+\beta_{i} \hat{f}_{i, t}+\varepsilon_{i, t}$ for $t=1, \ldots, T$. This forecast takes the form $\hat{y}_{i, T+1}=\hat{\beta}_{0 i, T}+\hat{\beta}_{i, T} \hat{f}_{i, T+1}$, where $\left(\hat{\beta}_{0 i, T}, \hat{\beta}_{i, T}\right)$ denote the OLS regression coefficients associated with using all data releases up to the $i$ th data release using observations $t=1, \ldots, T$.

We described the time-varying approach as intuitive because we update the index weights $w_{1, T}^{(i)}, \ldots, w_{i, T}^{(i)}$ and "model" $y_{t}=\beta_{0 i}+\beta_{i} \hat{f}_{i, t}+\varepsilon_{i, t}$ as we move across data releases, as is typically done in forecasting. In contrast, our second method might seem less intuitive because we really have only one set of weights and one common model that we use throughout the quarter. In this approach, we estimate the weights once using all 68 surprises obtained throughout the entire quarter. The index weights and regression model coefficients are identical to those constructed using the time-varying approach when $i=68$. However, when we construct the value of the index $\hat{f}_{i, T+1}$ in quarter $T+1$, we layer in an additional assumption-that any surprises arriving later in the quarter will all be zero. This implies that for each $i$, 


\section{Grover, Kliesen, McCracken}

Figure 4

Weights at the End of the First, Second, and Third Months of the Quarter (2015:Q4)
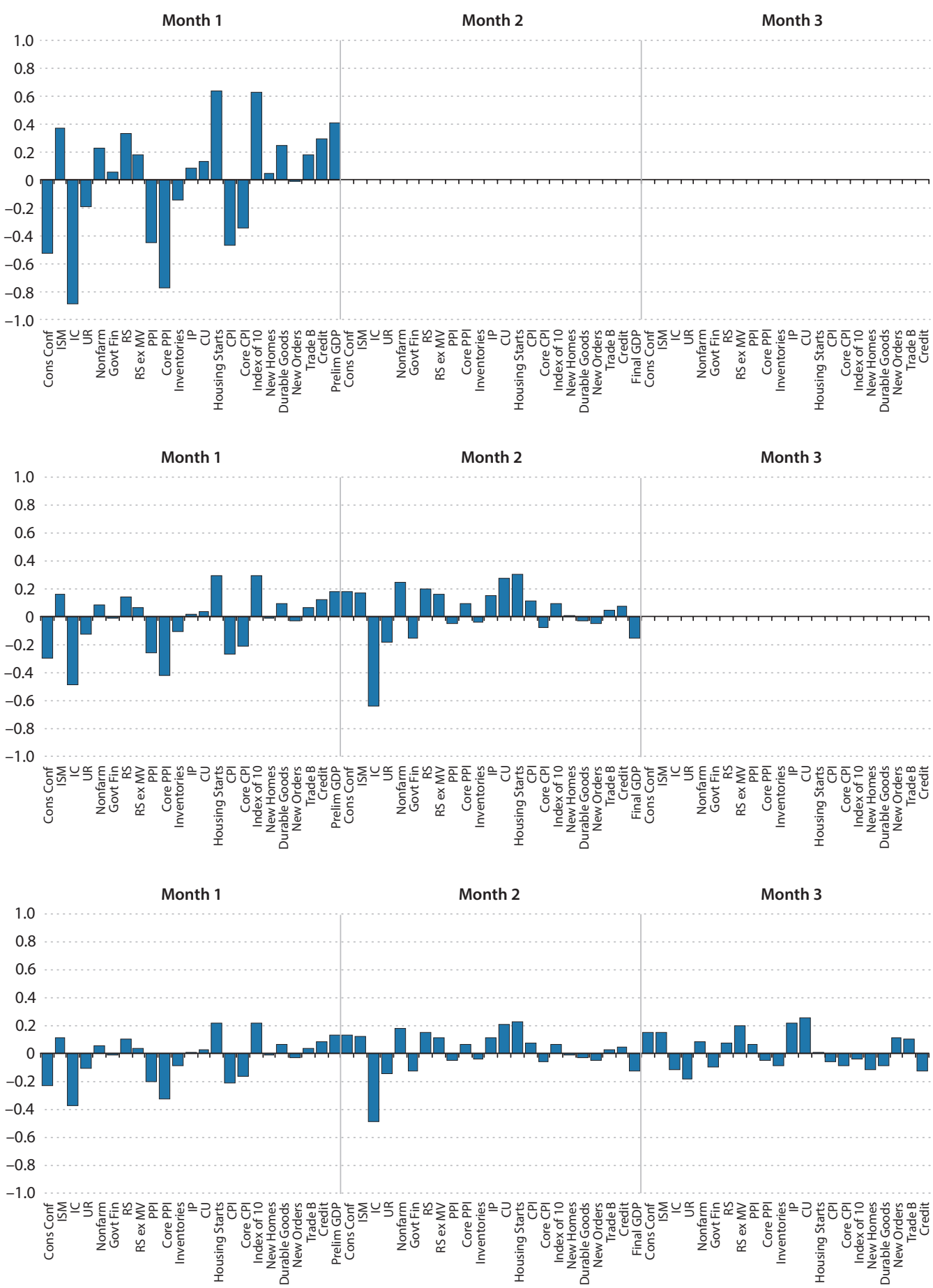

NOTE: The ordering of the series is consistent with that in Figure 3. 


$$
\hat{f}_{i, T+1}=w_{1, T}^{(68)} x_{1, T+1}+\ldots+w_{i, T}^{(68)} x_{i, T+1} \text { and } \hat{y}_{i, T+1}=\hat{\beta}_{0,68, T}+\hat{\beta}_{68, T} \hat{f}_{i, T+1} .
$$

Figure 4 plots the weights for each of the 68 series when estimated using surprises observed through the end of the first, second, and third data-release months of 2015:Q4. For this exercise, the dependent variable is defined using the advance release of GDP. The ordering is consistent with that in Figure 3. A few notable features from Figure 4 are worth highlighting.

i. The weights for a given predictor can be positive or negative depending on when the data are released within the quarter. For example, at the end of the first month, the surprise associated with the first release of the new home sales variable is given a positive weight of 0.05 and at the end of the second month, the weight associated with the second release of new home sales is given a positive weight of 0.004 . But at the end of the third month, the weight given to the third release of new home sales is set at -0.11 .

ii. The weights associated with a predictor in a given month can change magnitude as the weights are updated across the quarter. For example, the weight on the surprise component of industrial production in the first month of the quarter changes from 0.08 , to 0.01 , to 0.001 when the weights are re-estimated at the end of the three months. Put differently, while the first industrial production release of the quarter remains a positive signal for the quarter, its importance declines as we move within a quarter.

iii. The magnitudes of the weights for a given data release depend on when the release occurs within the quarter. As an example, the weights on the most recent industrial production release vary from 0.08 , to 0.15 , to 0.22 as we transition from the first through the third months of the quarter. Apparently, an unexpected positive surprise to industrial production means more later in the quarter than earlier in the quarter.

iv. In many cases the signs are intuitive: Initial claims always has a negative sign.

Capacity utilization always gets a positive sign. The ISM always gets a positive sign. Even so, there are some oddities. As an example, while consumer confidence always gets a negative weight in the first month, it always gets a positive weight in the second and third months.

\section{Economic News Index Plots}

While the weights are modestly interesting in their own right, the ultimate goal is to construct the ENI itself. Figure 5 provides examples of the paths of this index across 2015:Q4 for each of the two weighting schemes using the advance release of GDP to define the dependent variable. For some perspective on the variability in these paths, we also provide a shaded area that represents the range of the pointwise 5th and 95th percentiles of the empirical distribution of all paths dating back to 2000:Q1. $\frac{15}{1}$ The solid gray line in the middle of the shaded area represents the pointwise median of the historical paths. Since the horizontal axis reads through time with respect to the data release ordering, and the index is zero mean by construction, the vertical axis can be interpreted as indicative of whether the incoming data have on net come in stronger or weaker than expected as of the most recent data release. 


\section{Grover, Kliesen, McCracken}

Figure 5

\section{Historical Paths of the Economic News Index}

\section{A. ENI Using Fixed Weights}

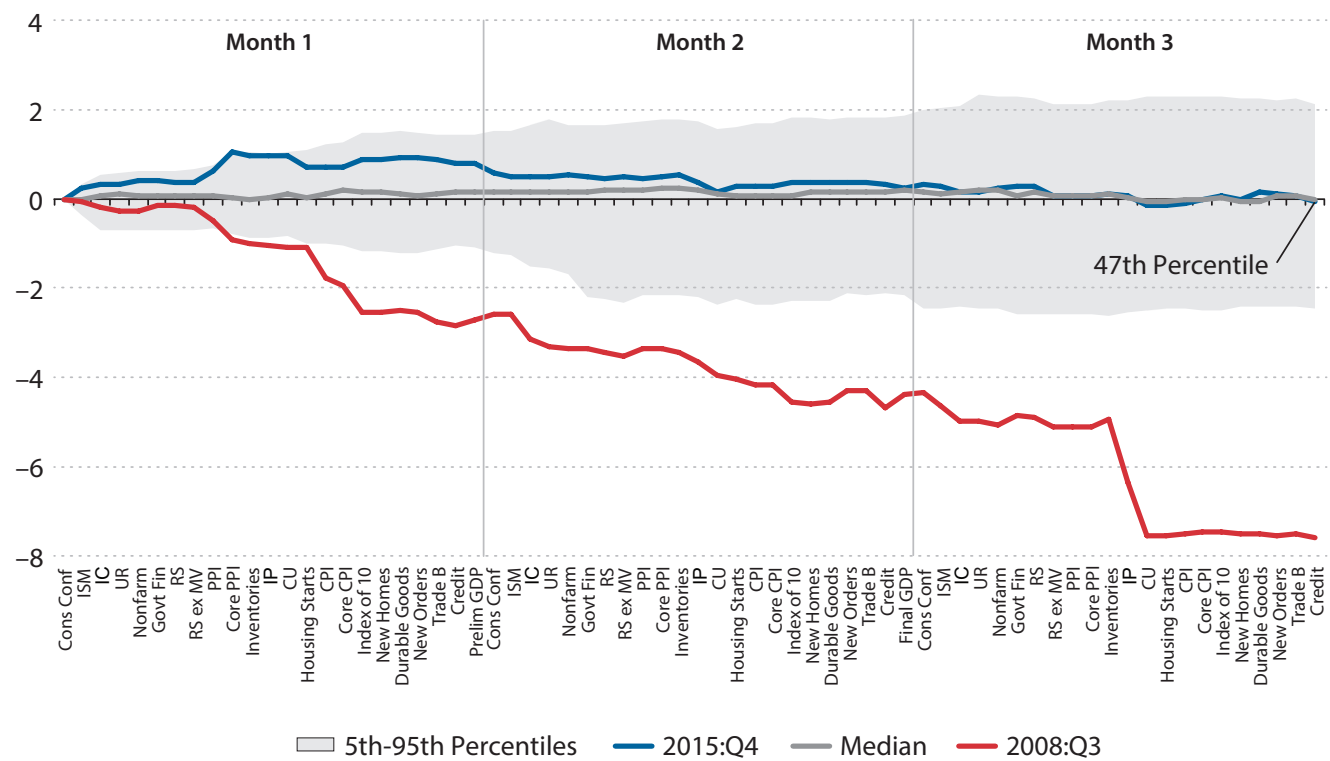

\section{B. ENI Using Time-Varying Weights}

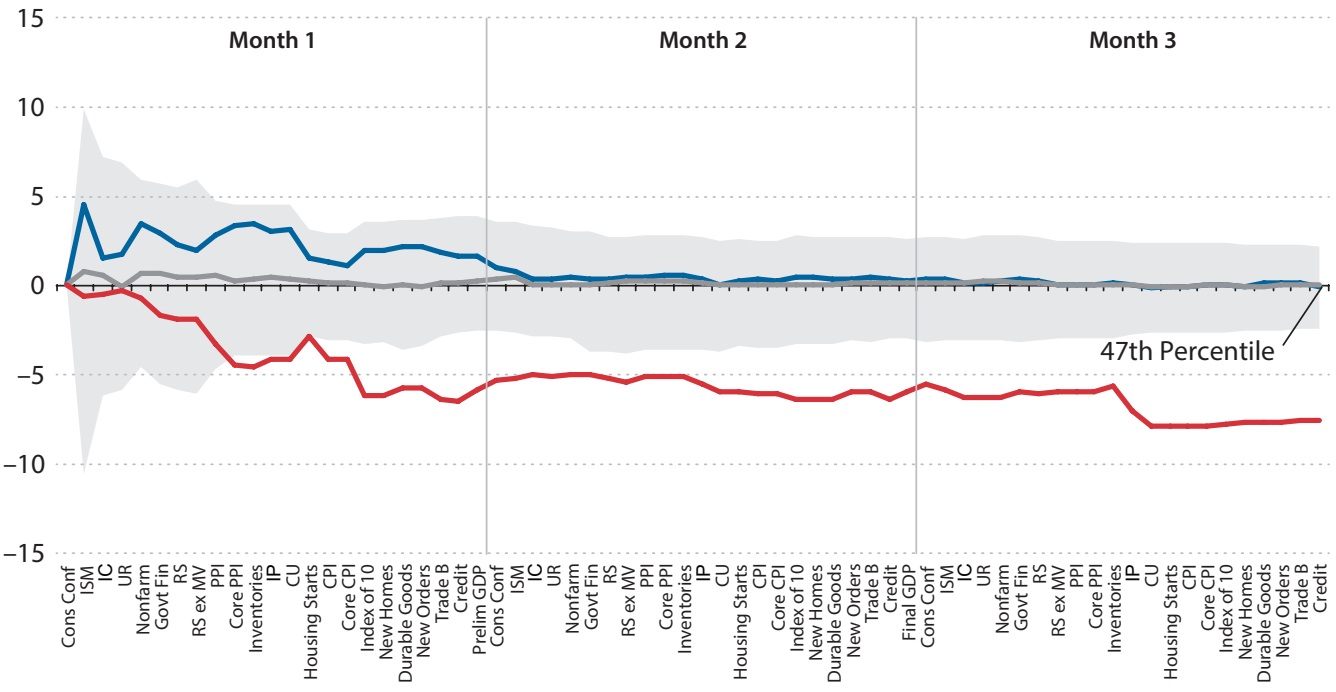

NOTE: The ordering of the series is consistent with that in Figure 3. 
Panel A of Figure 5 shows the paths for the ENI constructed using fixed weights. As we move across the quarter, the 5 th and 95 th percentiles tend to spread out monotonically, reaching levels near \pm 2 by the end of the quarter. Throughout the quarter the distribution of paths seems to be fairly symmetric around zero, which is the mean value of the index. Perhaps not surprisingly, the median path lies near the mean, though we should note there are no restrictions imposing such.

Panel B of Figure 5 provides the same type of plot but for weights re-estimated across the quarter. The main difference between this plot and the previous one is that in this case, the shaded area immediately spikes outward at the beginning of the quarter. Apparently there is a lot of variance associated with estimating the ENI when very few data releases are available to construct the index. While reasonably intuitive, this variance is not predetermined in any way. As more information becomes available, variability in the index declines before converging at levels near \pm 2 by the end of the quarter.

In both panels, we also plot the path of the ENI for 2015:Q4. In both cases, the incoming data during the month of November were suggestive of upward revisions in the BCC forecast. But as we proceeded into December, the index slowly began to decline before essentially converging to zero by the time we got into January 2016. At this point, the index was indicating that, on net, the incoming data had been neutral and the original BCC forecast was on target.

In both panels, we also plot the path of the ENI as we moved across 2008:Q3. We emphasize this path because it gives some indication of how the ENI behaves in an "abnormal" period such as the one the economy experienced heading into the Great Recession. During the first few weeks of August 2008, the index behaved relatively normally, lying well within the 5th and 95th percentiles. But by the time of the first release of industrial production, the ENI had declined sharply and continued to decline consistently until the third release of industrial production - at which point the ENI collapsed. Not surprisingly, following the first release of industrial production, nearly the entire path forms the lower bound of the empirical distribution of all paths of the ENI since 2000:Q1.

The upper tail of the empirical distribution of paths of the ENI is not so clearly defined by a singular event. In unreported results, we are able to establish that roughly two-thirds of the maximal values of the index are achieved in either 2001:Q4 or 2006:Q1. In the former, the BCC forecast was -1.9 percent, while the advance release was 0.2 percent. For the latter, the BCC forecast was 4.1 percent, while the advance release was 4.8 percent. In both cases, the path of the ENI suggested upward revisions to the BCC nowcast of current-quarter real GDP growth.

\section{FORECASTING EXPERIMENTS}

In this section, we provide empirical evidence on the usefulness of the ENI as a predictor for current-quarter real GDP growth. To do so, we perform a sequence of pseudo out-ofsample nowcasting exercises starting in 2010:Q1 and proceeding through 2015:Q4. This gives us 24 quarters of forecasts for each of the 68 data releases. For each release we consider forecasts made using the time-varying weights and forecasts made using the fixed weights. In addition, we consider two dependent variables: one defined using the advance release of real GDP and one defined using the first revision. 


\section{Grover, Kliesen, McCracken}

\section{Figure 6}

\section{Forecast Accuracy for Advance GDP Estimate (2010:Q1-2015:Q4)}

\section{A. Squared Errors: Fixed Weights}

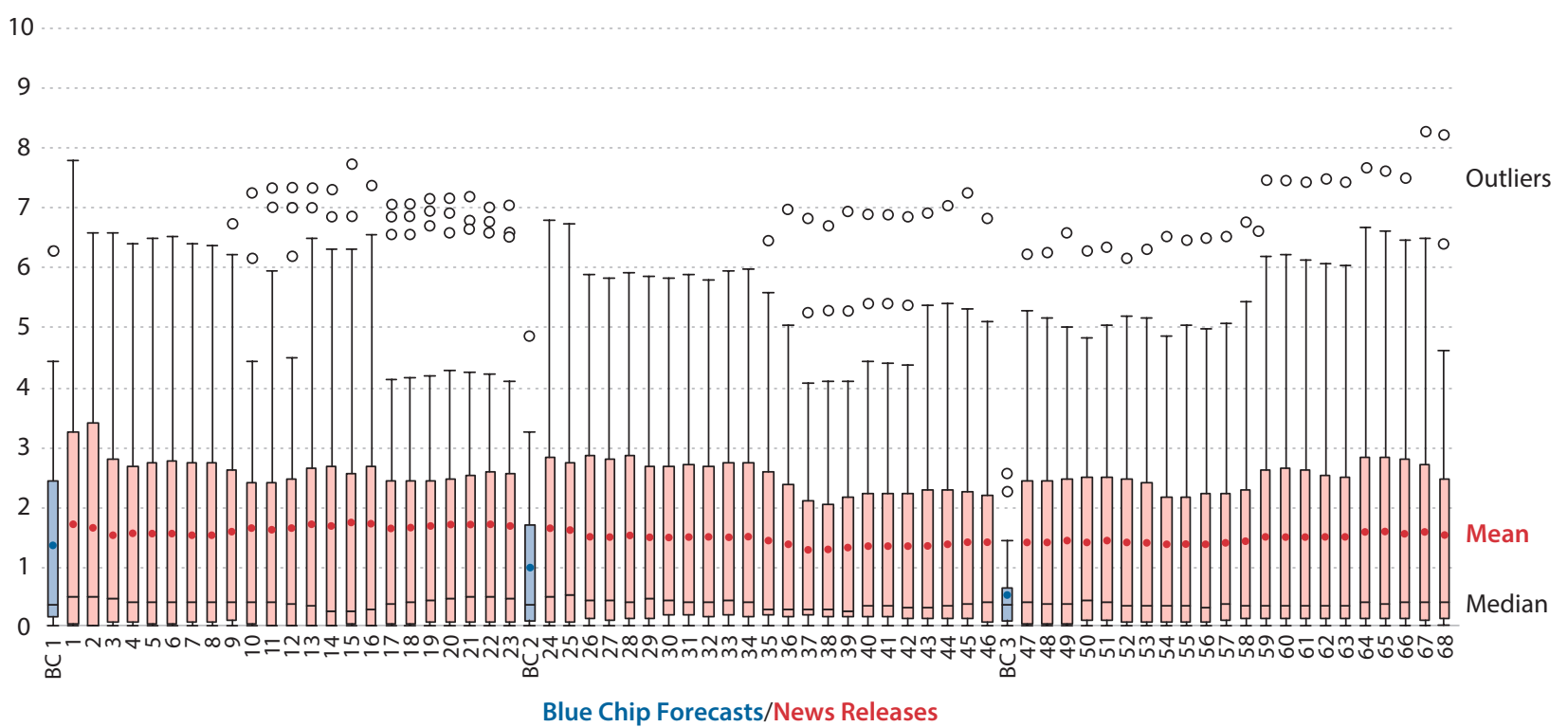

\section{B. Squared Errors: Time-Varying Weights}

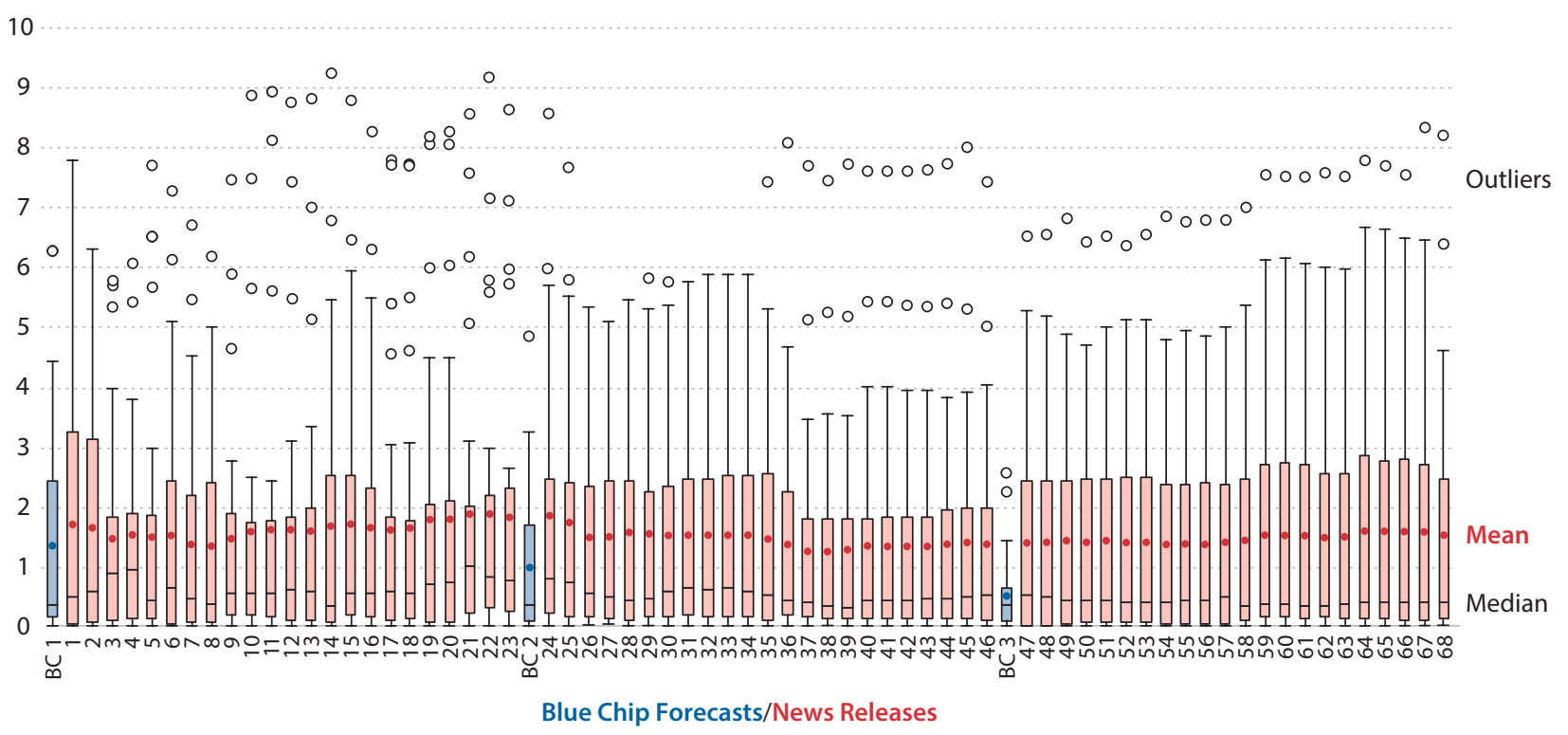

NOTE: The news release numbers reflect the ordering of series in Figure 3. BC, Blue Chip. 
Figure 7

Forecast Accuracy for First Revision of GDP Estimate (2010:Q1-2015:Q4)

\section{A. Squared Errors: Fixed Weights}

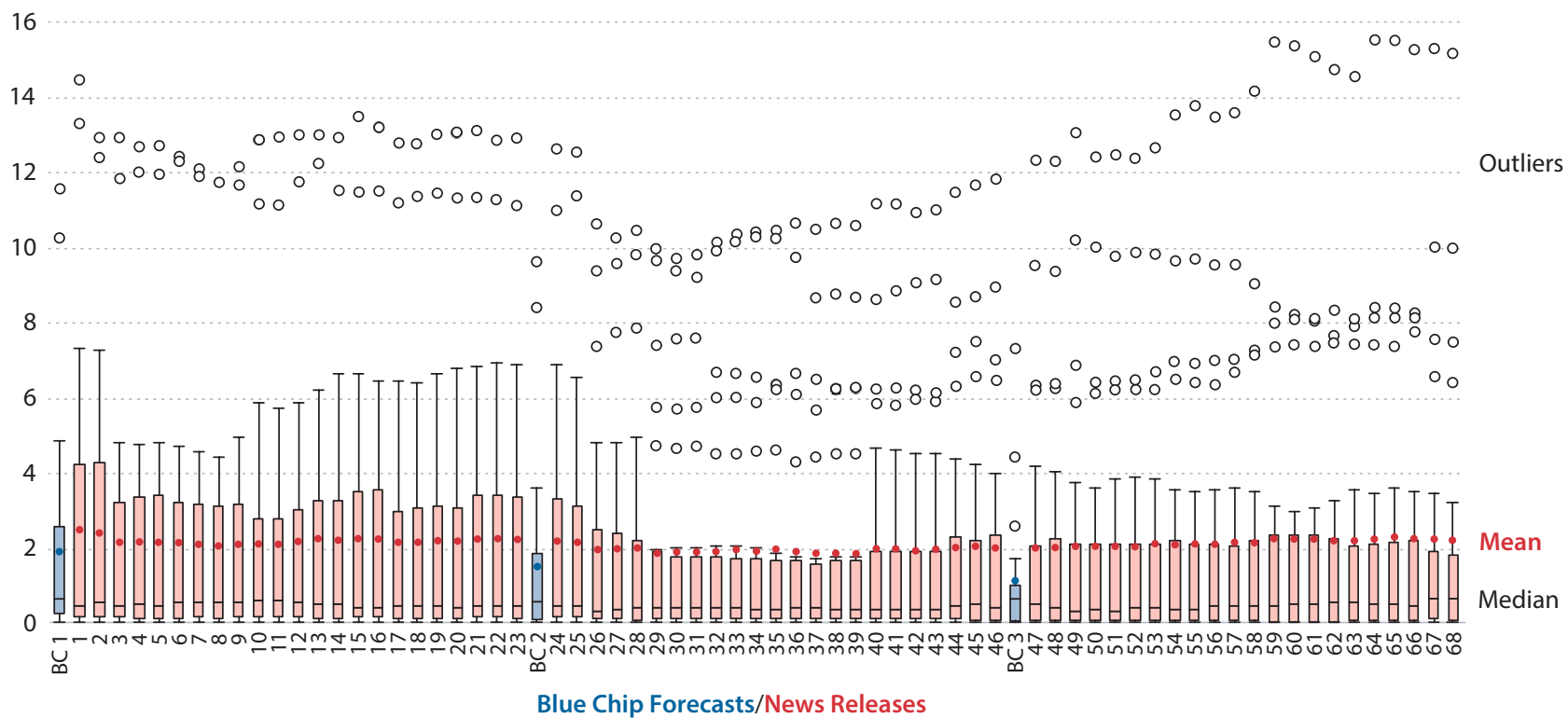

\section{B. Squared Errors: Time-Varying Weights}

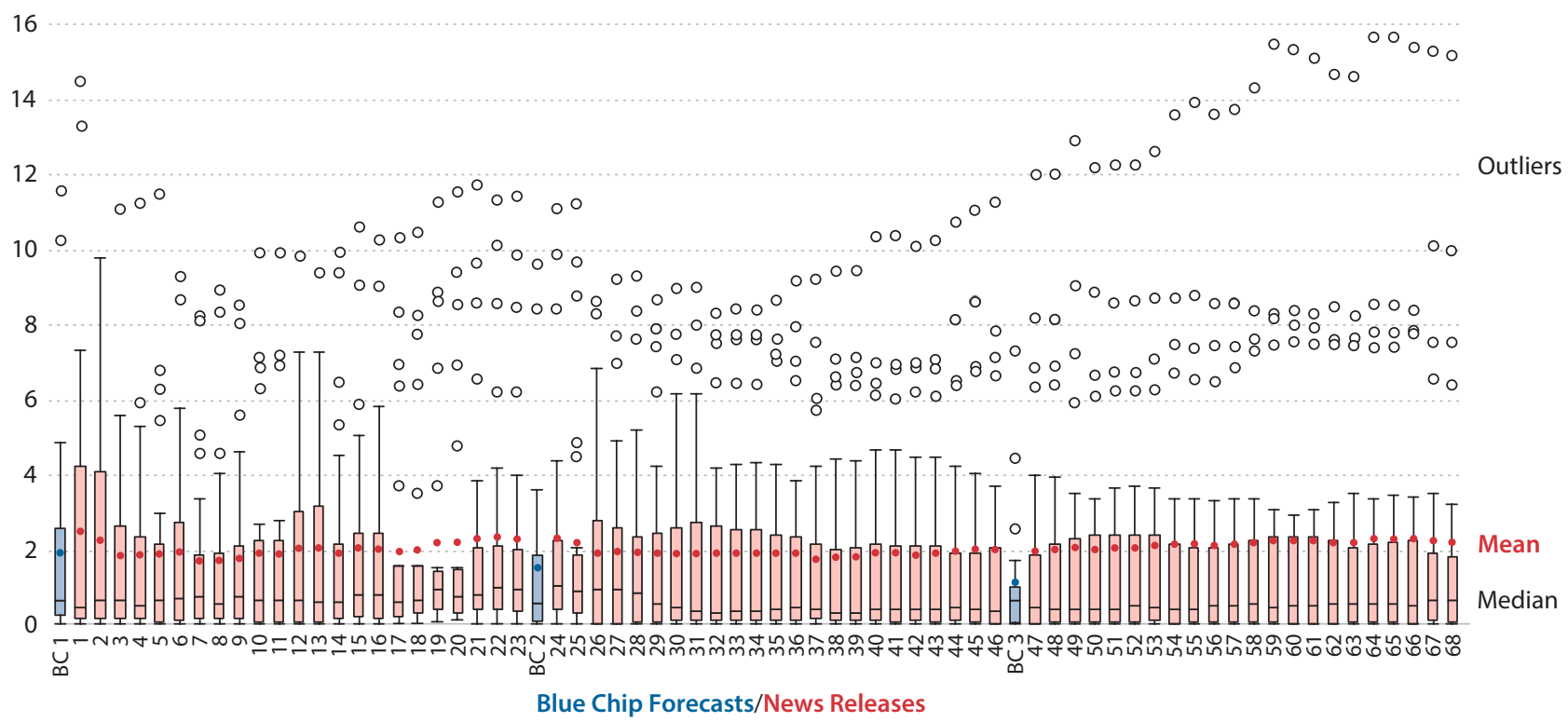

NOTE: The news release numbers reflect the ordering of series in Figure 3. BC, Blue Chip. 
Figure 8

Median Squared Errors for Advance GDP Estimate (2010:Q1-2015:Q4)

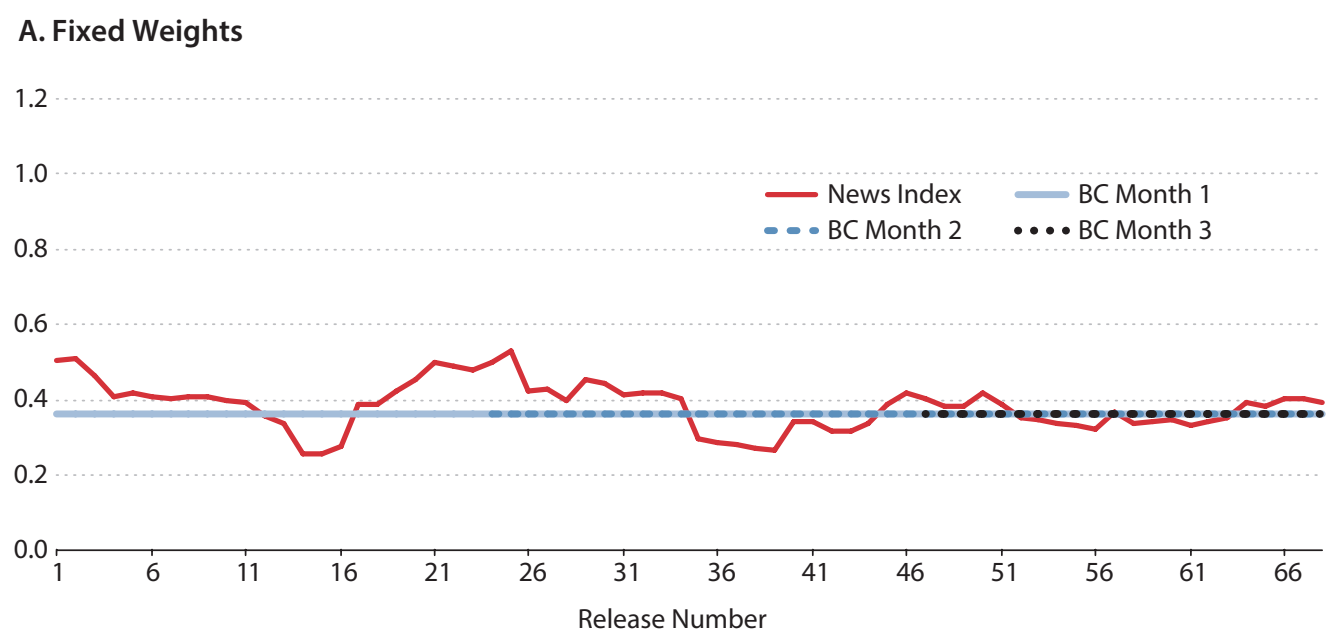

B. Time-Varying Weights

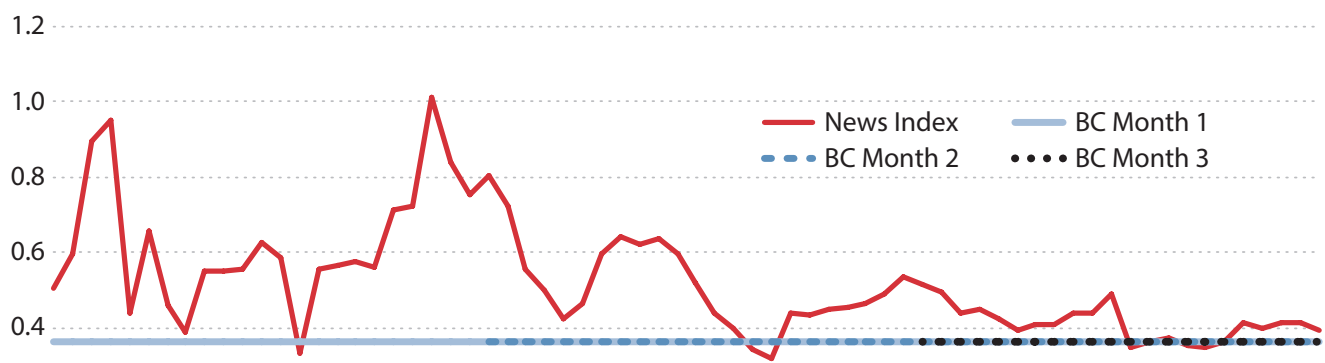

0.2

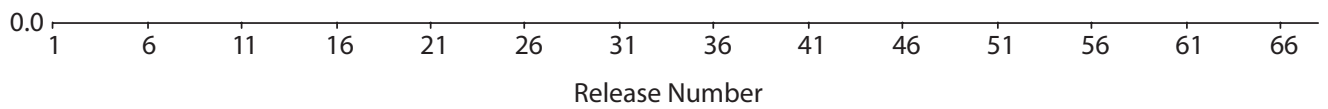

NOTE: The news release numbers reflect the ordering of series in Figure 3. BC, Blue Chip.

For each permutation of the weights, the data release, and the dependent variable we obtain 24 squared forecast errors. Figures 6 and 7 show these using box-and-whisker plots. For comparison, we also construct the same for the three BCC forecasts-one for each month-and insert them at the beginning of each data-release month across the quarter. In each box-and-whisker plot a shaded rectangle (box) represents the range from the 25th to 75th percentile, a dash within the rectangle represents the median, and a solid circle represents the mean. Vertical lines (whiskers) extending out of each box represent the spread of observations 1.5 interquartile ranges above the 75 th percentile or below the 25 th percentile. $\frac{16}{}$ Open circles outside the range of the whiskers represent outliers. 


\section{Figure 9}

\section{Median Squared Errors for First Revision of GDP Estimate (2010:Q1-2015:Q4)}

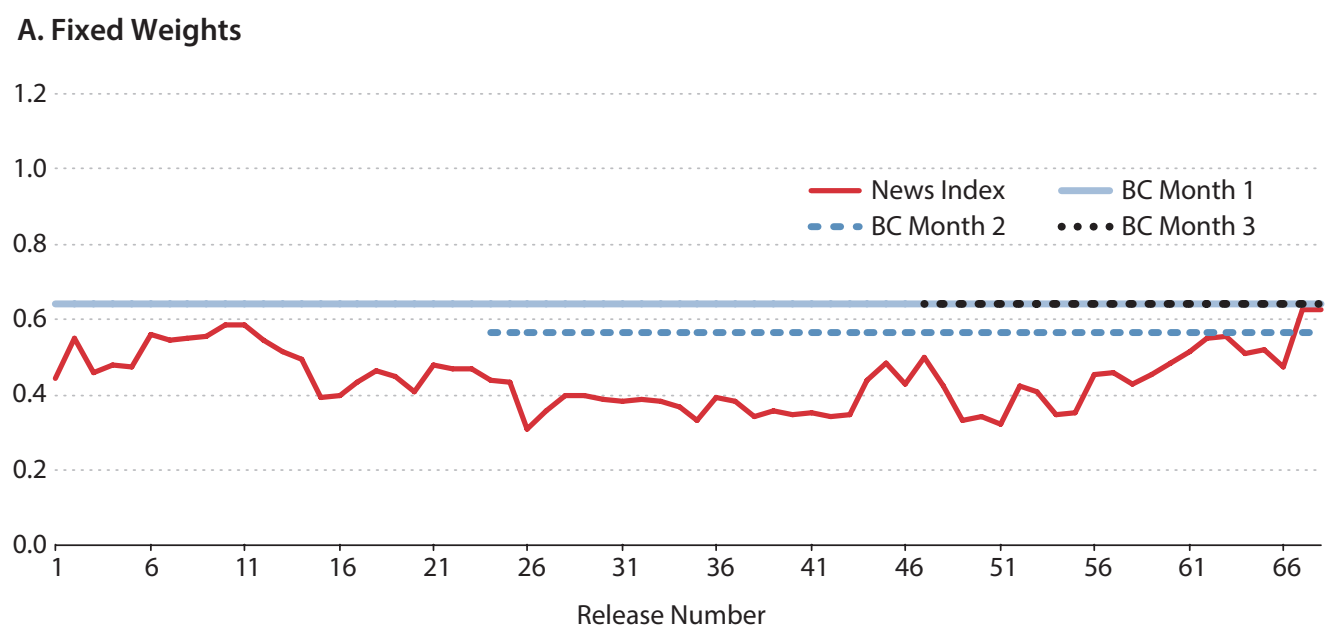

B. Time-Varying Weights

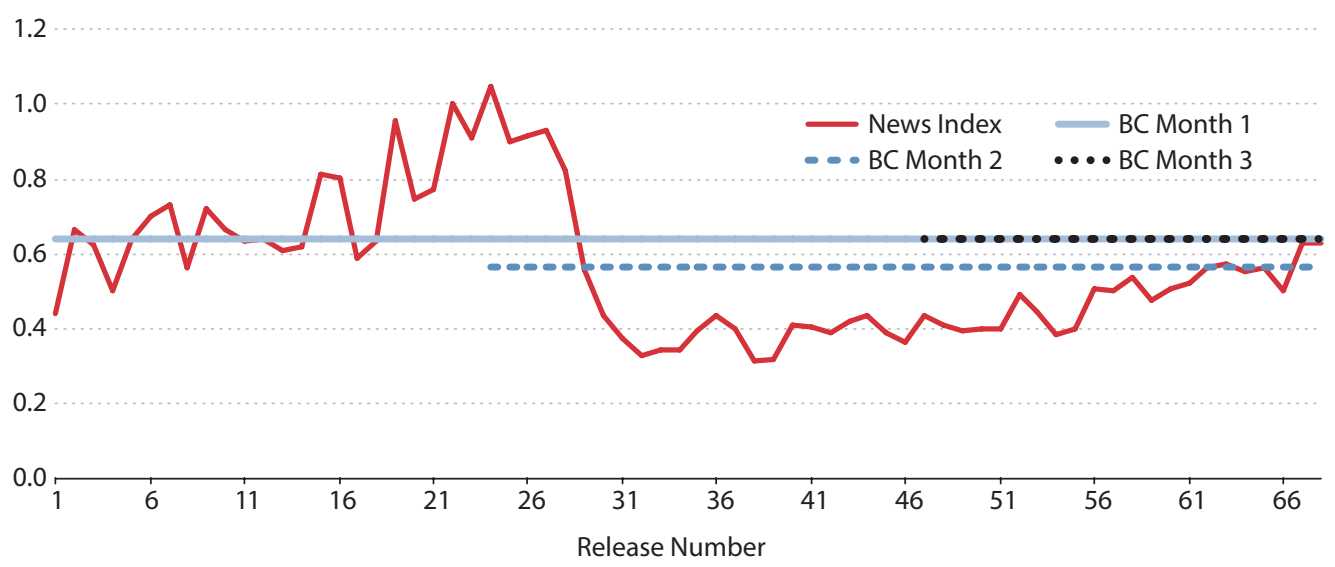

NOTE: The news release numbers reflect the ordering of series in Figure 3. BC, Blue Chip.

There are a number of takeaways from these plots. Perhaps the most obvious is the cloud of large outliers that exists for each plot. In most cases, there are more outliers associated with forecasts made from the news index than those that arise from the BCC forecasts. This is not surprising since the BCC is a consensus forecast and hence outlier forecasts are smoothed over by taking the median value from the survey. This immediately leads to the second observation that the mean squared errors associated with the ENI-based forecasts all tend to be much higher than those associated with the BCC forecast, especially moving into the second and third months of the quarter. 


\section{Grover, Kliesen, McCracken}

One interpretation of the plots is that the news index is not useful for prediction relative to the BCC forecasts. One could certainly reach that conclusion if we focused exclusively on the means of the distributions. But a closer look shows that the median squared errors from the news index are similar to and often lower than those associated with the BCC forecasts. This is particularly true when the target variable is constructed using the first revision of real GDP. To see this more clearly, consider Figures 8 and 9. Here we highlight the path of the median squared errors as we move across the quarter from one data release to the next. Note that we also do this separately for each of the three BCC forecasts across the quarter.

Figure 8 shows the paths for the median squared errors across data releases when the advance release of GDP is used to define the dependent variable. Panel A shows the paths constructed with fixed weights, while Panel B shows those constructed with time-varying weights. When fixed weights are used, the news index usually performs about the same as the BCC (which just happens to have the same median squared error regardless of which month within the quarter it is released). This is less true when time-varying weights are used to construct the index. In fact, the median squared error is very volatile during the first month-a not unexpected outcome given the volatility in the historical paths indicated in the shaded region on Panel B of Figure 5.

Figure 9 reports the same median squared error paths as Figure 8 but uses the first revision of GDP to define the dependent variable. Here we find that when fixed weights are used, the news index usually performs better than the BCC and does so at nearly all intraquarter horizons. And when the time-varying weights are used, the news index tends to perform better than the BCC but only during the second and third months of the quarter.

\section{CONCLUSION}

In this article, we introduce an economic news index (ENI) intended for use as an input for constructing nowcasts of current-quarter real GDP growth. The index is a weighted average of the "news" that arrives throughout the current quarter as various macroeconomic data are released. The weights are chosen relative to the predictive content of that news event for current-quarter real GDP growth using the three-pass regression filter developed in Kelly and Pruitt (2015). As such, at any given time throughout the quarter, a positive value of the index suggests that, on net, the incoming news has been better than expected for real GDP growth and vice versa if the index value is negative.

We evaluate the predictive content of the index using a variety of forecasting exercises. The results indicate that relative to the BCC forecasts of real GDP growth, the ENI can sometimes be volatile and produce forecasts that are very inaccurate. And because even a few very inaccurate forecasts can affect the mean squared error, it is almost always the case that the BCC forecast has a lower mean squared error than that associated with the ENI-based forecast. If instead we use an outlier-robust measure of accuracy, like the median squared error, we find that especially when forecasting the first revised value of real GDP growth, the ENIbased forecast is often more accurate than the BCC. 


\section{NOTES}

1 For a discussion of these and other related issues from an economic policymaking perspective, see Deutsche Bundesbank (2013).

$\underline{2}$ The BEA keeps two accounts. The first measures the dollar value (both in current dollars and in chain-weighted, or real, dollars) of expenditures on goods, services, and structures produced in the United States (GDP). The second account measures the income that flows to the owners of the factors of production (labor, land, and tangible capital) used to produce the output and expenditures measured by GDP. The latter is termed "gross domestic income" (GDI). In theory, GDP and GDI should equal each other. In practice, they differ by a residual. The data are also adjusted to remove any regularly occurring seasonal variation. We focus on the expenditure-side estimate (GDP) in this article.

$\underline{3}$ For example, see the Federal Reserve Bank of Atlanta's GDPNow current-quarter forecast at https://www.frbatlanta.org/cqer/research/gdpnow.aspx?panel=1.

4 For a discussion of how the BEA pieces together the National Income and Product Account data, see the BEA's Methodology Papers at http://www.bea.gov/methodologies/.

5 See Chauvet and Potter (2013) and Giannone, Reichlin, and Small (2008). Jackson, Kliesen, and Owyang (2015) forecast inflation using a factor-augmented vector autoregression.

6 For example, in the December 16, 2015, FOMC Press Release, the Committee noted that "the actual path of the federal funds rate will depend on the economic outlook as informed by incoming data." See http://www.federalreserve.gov/newsevents/press/monetary/20151216a.htm.

7 Four times per year, the FOMC participants release their economic projections for real GDP growth, inflation, the unemployment rate, and their expectation for the federal funds rate at the end of the current year and several subsequent years. These are known as the Summary of Economic Projections (SEP). For example, the version of the SEP associated with the December 15-16, 2015, meeting can be found at http://www.federalreserve.gov/monetarypolicy/fomcprojtabl20151216.htm.

8 This concept is developed and further explained in Kliesen (2014).

9 The source and non-source GDP data referenced in this article can be found in the Federal Reserve Bank of St. Louis's FRED ${ }^{\circledR}$ database. FRED, an acronym for Federal Reserve Economic Data, is one of the world's largest collections of freely available economic and financial data. FRED can be accessed at https://fred.stlouisfed.org.

10 The term "current quarter" is somewhat misleading. For example, the advance estimate of real GDP growth in the fourth quarter of 2015 is not released until late January 2016. Accordingly, data for December 2015 are still being released in January 2016. In fact, some of the source data for fourth-quarter 2015 are not released until after the advance estimate in late January.

11 Median forecasts and data releases are accessed through Haver Analytics. Forecasts prior to December 15, 2003, are from MMS International.

12 One can think of this two-step approach as an ad hoc way of allowing for a time-varying intercept in a predictive regression but where the intercept is known to be the BCC forecast. Such an approach is not without precedent. For example, the FRB/US model (see https://www.federalreserve.gov/econresdata/frbus/us-models-about.htm) defines the dependent variable in its inflation equation as the deviation of realized inflation from a forecast taken from the Survey of Professional Forecasters. See Kozicki and Tinsley (2001) and Clark and McCracken (2010) for other examples.

13 For statistical considerations and asymptotic properties, refer to Kelly and Pruitt (2015).

14 Note too that we do not impose any cross-month restrictions on the weights, and hence it is possible that at the end of March the weight given to the surprise component of industrial production obtained in February can be positive, while that obtained in March can be negative.

15 The paths are estimated as "real-time" forecasts. For example, the 2000:Q1 path is calculated using data up to 1999:Q4.

16 The interquartile range is the distance between the 75 th and 25 th percentiles. 


\section{Grover, Kliesen, McCracken}

\section{REFERENCES}

Bańbura, Marta; Giannone, Domenico; Modugno, Michele and Reichlin, Lucrezia. "Now-Casting and the Real-Time Data Flow," in Graham Elliott and Allan Timmermann, eds., Handbook of Economic Forecasting. Volume 2A. Chap. 4. Amsterdam: North-Holland, 2013, pp. 195-237; http://dx.doi.org/10.1016/B978-0-444-53683-9.00004-9.

Brave, Scott A. and Butters, R. Andrew. "Nowcasting Using the Chicago Fed National Activity Index." Federal Reserve Bank of Chicago Economic Perspectives, First Quarter 2014, 38(1), pp. 19-37; https://www.chicagofed.org/publications/economic-perspectives/2014/1q-brave-butters.

Chauvet, Marcelle and Potter, Simon. "Forecasting Output," in Graham Elliott and Allan Timmermann, eds., Handbook of Economic Forecasting. Volume 2A. Chap. 3. Amsterdam: North-Holland, 2013, pp. 141-94; http://dx.doi.org/10.1016/b978-0-444-53683-9.00003-7.

Clark, Todd E. and McCracken, Michael W. "Averaging Forecasts from VARs with Uncertain Instabilities." Journal of Applied Econometrics, January-February 2010, 25(1), pp. 5-29; http://dx.doi.org/10.1002/jae.1127.

Deutsche Bundesbank. "Forecasting Models in Short-Term Business Cycle Analysis." Monthly Report, September 2013, 65(9), pp. 69-84; https://www.bundesbank.de/Redaktion/EN/Downloads/Publications/Monthly Report/2013/2013 09 monthly report.html.

Giannone, Domenico; Reichlin, Lucrezia and Small, David. "Nowcasting: The Real-Time Informational Content of Macroeconomic Data." Journal of Monetary Economics, May 2008, 55(4), pp. 665-76; http://dx.doi.org/10.1016/j.jmoneco.2008.05.010.

Jackson, Laura E.; Kliesen, Kevin L. and Owyang, Michael T. "A Measure of Price Pressures." Federal Reserve Bank of St. Louis Review, First Quarter 2015, 97(1), pp. 25-52; https://research.stlouisfed.org/publications/review/2015/q1/25-52JacksonKliesenOwyang.pdf.

James, Jessica and Kasikov, Kristjan. "Impact of Economic Data Surprises on Exchange Rates in the Inter-Dealer Market." Quantitative Finance, February 2008, 8(1), pp. 5-15; http://dx.doi.org/10.1080/14697680701446195.

Kelly, Bryan and Pruitt, Seth. "The Three-Pass Regression Filter: A New Approach to Forecasting Using Many Predictors." Journal of Econometrics, June 2015, 186(2), pp. 294-316; http://dx.doi.org/10.1016/j.jeconom.2015.02.011.

Kliesen, Kevin L. "A Guide to Tracking the U.S. Economy." Federal Reserve Bank of St. Louis Review, First Quarter 2014, 96(1), pp. 35-54; https://research.stlouisfed.org/publications/review/2014/q1/kliesen.pdf.

Kozicki, Sharon and Tinsley, P.A. "Shifting Endpoints in the Term Structure of Interest Rates." Journal of Monetary Economics, June 2001, 47(3), pp. 613-52; http://dx.doi.org/10.1016/S0304-3932(01)00054-X.

Stock, James H. and Watson, Mark W. "Forecasting with Many Predictors," in Graham Elliott, Clive W.J. Granger and Allan Timmermann, eds., Handbook of Economic Forecasting. Volume 1. Chap. 10. Amsterdam: North-Holland, 2006, pp. 515-54; http://dx.doi.org/10.1016/S1574-0706(05)01010-4. 